\title{
CAMILO HENRÍQUEZ: TEATRO, REPUBLICANISMO Y MODERNIDAD
} Camilo Henríquez: theater, republicanism and modernity

\author{
Bernardo Subercaseaux y Paula Cuadra
}

Resumen

El artículo examina la obra teatral de fray Camilo Henríquez, específicamente La Camila o la Patriota de Sudamérica, a partir del supuesto de que en esta los principios estéticos quedan subordinados al ideario ilustrado y republicano, a cuya defensa y difusión fray Camilo dedicó su vida. A partir del análisis de la obra se develan las diferentes marcas textuales por las que el autor publicita las ideas republicanas e instala -en un modelo de asimilación- a un sujeto indio moderno. Operación que se da en un contexto de recepción en que colonialidad y modernidad son fenómenos simultáneos, lo que deviene a la postre en un pensamiento republicano utópico.

Palabras clave: Sujeto moderno. Pensamiento republicano. Modernidad. Sociabilidad. Asincronía.

Abstract

This article approaches the work of Friar Camilo Henríquez, specifically the play The Camila or the Patriot of South America, from the assumption that aesthetic principles are subordinate to the illustrated modern and republican ideas, who Fray Camilo devoted most of his life to defend and disseminate. From the analysis of La Camila, the article unveils the different textual marks through which the author disseminated republican ideas and established, in an assimilation fashion, a modern Indian subject. This happens in a reception context in which colonialism and modernity appear to be simultaneous, and therefore republican thought becomes utopian.

Key words: Modern subject. Republican thought. Modernity. Sociability. Asynchrony.

\section{TEATRO O DOCUMENTO}

Fray Camilo Henríquez (1769-1825) es conocido sobre todo como publicista de la Independencia (Proclama de Quirino Lemachez) y como periodista y editor del primer periódico publicado en el país (La Aurora de Chile, 1812-1813), pero escasamente como dramaturgo. De hecho, las dos piezas que escribió en su exilio argentino (1815-1822) nunca han sido representadas en su totalidad. La inocencia en el asilo de las virtudes (que se sitúa en Filadelfia) solo se encuentra en formato manuscrito $^{2}$, y La Camila o la Patriota de Sudamérica fue publicada en 1817, en Buenos Aires. La Sociedad del Buen Gusto, una organización de la sociedad civil bonaerense cuyo fin era velar por la calidad teatral y por educar a los espectadores, no le

\footnotetext{
${ }^{1}$ Bernardo Subercaseaux. Investigador Responsable Proyecto Fondecyt "Modernidad, modernización y cultura en América Latina" ( $\left.\mathrm{N}^{\circ} 1130031\right)$. Paula Cuadra, alumna ayudante.

${ }^{2}$ Véase en www.memoria chilena.cl
} 
concedió auspicio ni la difundió (lo que fue explicado en términos cualitativos ${ }^{3}$ ). $L a$ Camila, sin embargo, fue reeditada en 1912 por Nicolás Peña como parte del proyecto Biblioteca de Escritores de Chile para conmemorar el Centenario ${ }^{4}$, y ha sido puesta en escena a propósito del Bicentenario (2010) en una mixtura de cuatro piezas nacionales dirigida por Ramón Griffero 5 .

Miguel Luis Amunátegui, primer biógrafo del sacerdote, vio en Camila, la joven protagonista, a un Camilo Henríquez con falda. Dijo que bajo la capucha monacal del Fraile se ocultaba una cabeza en que bullían las ideas de los librepensadores dieciochescos. Eugenio Pereira Salas señaló que los personajes eran ventrílocuos de las ideas del autor. Andrés Sabella sostuvo que el "político" avasalló al "escritor". Y Luis Pradenas afirmó que La Camila no dejó entonces ni deja ahora buena impresión porque había en su argumento muchas disertaciones y poca acción (Pradenas).

Es posible señalar que el contexto de producción teatral en la década inmediata a la Independencia favorecía el teatro patriótico, Bernardo O'Higgins nombrado Director Supremo tras la victoria de Chacabuco (1817), así como otros próceres de la Independencia, concebía al teatro "como una institución social cuyo principal objetivo era propagar las máximas patriotas y formar las costumbres cívicas", de hecho O’Higgins dictó un decreto señalando que cada representación teatral debía comenzar con el himno nacional como afirmación patriótica (Faúndez).

A este afán patriótico se sumaba un contexto de producción teatral que se regía por los principios neoclásicos al uso, presentes en autores como Horacio, Boileau y Blair. En La Aurora de Chile, fray Camilo difundió las ideas de Hugo Blair, clérigo escoces autor de Lecciones sobre la retórica y las bellas letras (1783), compendio del buen escribir cuya síntesis traducida tuvo uso docente en el Instituto Nacional. Se señala, sin embargo, que durante la Patria Vieja - en que todavía existía incertidumbre acerca de la emancipación de las antiguas colonias- a Camilo Henríquez y a los ilustrados republicanos les importaba sobre todo la palabra escrita y la cultura letrada no en función de las "bellas letras", sino en su potencial para la educación cívica y patriótica. Por esta razón, a lo largo de todo el siglo XIX los intelectuales chilenos se esforzaron por desarrollar un conjunto de símbolos que permitieran instaurar y difundir la idea de Nación.

\footnotetext{
${ }^{3}$ La Sociedad del Buen Gusto, que funcionó entre 1817 y 1820, tenía una Comisión de Censura presidida por Manuel Belgrano. Los miembros de la sociedad estimaron poco atractivas las situaciones dramáticas, consideraron los personajes poco definidos y solo valoraron las proclamas políticas insertas en la obra.

${ }^{4}$ Nicolás Peña. "Prólogo". Teatro Dramático Nacional Tomo I. Santiago: Imprenta Barcelona, 1912. También es importante destacar que, por decreto de ley, la reedición de la pieza hecha por Peña fue distribuida en todos los establecimientos estatales de enseñanza, en la segunda década del siglo XX. Este antecedente resulta interesante a la hora de dilucidar la importancia del teatro en el contexto nacional.

${ }^{5}$ El dramaturgo y director Ramón Griffero dirigió Chile BI-200, un montaje que mezcla cuatro obras: $L a$ Camila, o la patriota de Sud América (1817); La Independencia de Chile (1865), de José Antonio Torres; La batalla de Tarapacá (1883) de Carlos Segundo Lathrop y La República de Jauja (1889), de Juan Rafael Allende.

${ }^{6}$ La opinión de Andrés Sabella es citada por Leandro Urbina en La Camila o la patriota de Sud-América. 
Camilo Henríquez tenía plena conciencia de esta concepción instrumental de la literatura: "Yo considero el teatro - escribió- únicamente como escuela pública y bajo este respecto es innegable que la musa dramática es un gran instrumento en las manos de la política" (Henríquez, La Aurora 31, 130).

Pero precisamente este didactismo excesivo que releva lo estético a un lugar secundario y marginal es lo que le otorga a La Camila significación y valor como documento y fuente histórica, posibilitando que sea analizada como un compendio del pensamiento republicano, de ese pensamiento que compartieron Camilo Henríquez, Juan Egaña y Manuel de Salas, y también figuras señeras de la emancipación en Chile y América, como José Miguel Carrera y Simón Bolívar.

La filosofía política contemporánea distingue entre republicanismo y liberalismo, considerándolos como dos brazos diferentes del pensamiento ilustrado en América. La obra del fraile de la buena muerte permite perfilar los ideologemas fundamentales del pensamiento republicano y el desfase que se dio en la época de la Independencia entre las ideas modernas de un pequeño grupo de la élite criolla y la sociabilidad local; permite también hacerse cargo de la asincronía entre una utopía republicana y un contexto en que colonialidad y modernidad eran fenómenos simultáneos en el tiempo. Poner de relieve esa significación compleja es lo que pretendemos a partir del análisis de su única obra de teatro publicada. El supuesto del análisis es que tras los personajes y la acción de toda obra ficticia están las ideas, particularmente en una obra en que el pensar literario está fagocitado por el pensar conceptual y por una función de educación cívica y patriótica.

\section{DRAMA SENTIMENTAL Y POLÍTICO}

Drama sentimental en 4 actos, así se subtitula la obra. Más ajustado sería "drama político", en donde lo sentimental es un artificio para tensionar el conflicto histórico político y posibilitar extensos parlamentos en pro de la emancipación, la libertad y la soberanía, ideas que entonces se consideraban modernas. El asunto de la obra es la Primera Junta de Gobierno Autónoma y la matanza de Quito del 2 de agosto de 1810, en que fuerzas realistas provenientes de Lima asesinaron a varios patriotas que habían intentado en 1809 instalar una primera Junta de gobierno en reemplazo de la Real Audiencia, considerando el vacío de poder que se produjo en España a raíz de la invasión napoleónica. Las fuerzas realistas y algunos criollos que percibían esta Junta como una deslealtad con la monarquía de Fernando VII, luego de reprimir a los miembros de la Junta, y también a sus parientes, saquearon la ciudad dejando varios centenares de muertos. Camilo Henríquez, que había sido enviado a Quito por su orden religiosa a raíz de problemas con la Inquisición, fue testigo de esta matanza y en "Advertencias", especie de prólogo de la obra, consigna brevemente estos hechos y menciona a algunos criollos eminentes que fueron asesinados, dándole así sustento histórico al asunto que motivó la pieza. En medio de la confusión y el caos la desgraciada ciudad -dice- quedó de luto, "muchas familias ilustres huyeron a pie a los 
montes" (Henríquez, La Camila, 7). En los alrededores de Quito se está en un ambiente andino, y en realidad no se puede hablar de una selva. Esto implica que respecto del territorio en que tiene lugar la acción el autor llevó a cabo una operación de ficcionalización, una variación creativa de las coordenadas espaciales y del paisaje, que lo traslada desde la cordillera a la selva, hábitat en que se ocurre el drama.

La obra se focaliza en una de estas familias criollas, compuesta por don José, su mujer doña Margarita y su hija Camila, esta última sumida en la tristeza porque en Quito ha desaparecido don Diego, su marido, miembro de la Primera Junta, a quien presumen muerto, pero que, como veremos más adelante, reaparece con anagnórisis y todo. En cuanto a los españoles son, como personajes, solo una referencia, están ausentes como personajes pero presentes como amenaza.

No en los montes sino en los márgenes del río Marañón, en plena selva amazónica, instalados en una pequeña choza armada por ellos mismos, se encuentra la familia criolla que huye de los realistas. Desde las primeras escenas aparece el tópico de la naturaleza: doña Margarita manifiesta su miedo a las serpientes y tigres, dando así ocasión para que don José señale que bastante más sanguinarios y terribles que las fieras son los mandatarios españoles. Padre e hija proclaman el carácter bienhechor de la naturaleza, perfilándola como una instancia fecunda y sabia, tópico que por aquí y por allá está presente en toda la obra. También en los indígenas hay frecuentes alabanzas a la naturaleza, como plasmación del bien y de la belleza. Se trata en este caso de un ideologema ilustrado que permea los discursos letrados de la Independencia: la naturaleza cumulativa, cíclica y progresiva constituye un metarrelato que anticipa y es paradigma del desarrollo histórico. Naturaleza e historia forman parte de un decurso teleológico de la humanidad.

Luego de un largo monólogo en que Camila fustiga a "los verdugos de América" y alaba a quienes promueven la razón y el estudio, se descargan rayos y relámpagos (la luz), momento en que la protagonista advierte que "un salvaje baja por el monte; él ha divisado... - dice- nuestra chocita, y viene a ella a guarecerse" (Henríquez, La Camila, 14). La voz "salvaje" utilizada por Camila enaltece a contrario sensu a Yari, indígena que habla en perfecto español y no en una de las lenguas de la familia Tupi-guaraní, como es propio de los Omagua. Se trata además, como acota la voz autorial, de un "indio ilustrado" que se presenta como cuñado del Cacique de los Omagua, formado en el virreinato de Lima en tiempos de las reformas borbónicas. Luego de un largo parlamento en que señala que las pretensiones de España contradicen a la naturaleza, y "a la gran causa de la razón y la humanidad" (17), Yari invita a los criollos a visitar el poblado de los Omagua ${ }^{7}$, y a conocer al Cacique, quien resulta ser un sujeto moderno como lo es también el propio Yari. A punto de recibir a los criollos el

\footnotetext{
${ }^{7}$ Habitaban en la confluencia de los ríos Marañón y Ucayali, trasladándose entre el oeste de Brasil y el noreste peruano, forman parte de la familia lingüística tupi-guaraní. Durante la Conquista se los vinculó al mito del Dorado. Se trata de una etnia hoy casi desaparecida.
} 
Cacique abre el tercer acto con una reflexión que alude a la instalación de la modernidad en el continente:

“¿No fuera posible que empezase por aquí en Sud América el imperio de la razón y de las leyes sabias y paternales, como el blando resplandor de la aurora? Un pueblo nuevo, sin lujo, sin heredadas preocupaciones y costumbres, puede presentarse libre de aquellas máximas bárbaras, que por serie de siglos han hecho gemir a la humanidad" (Henríquez, La Camila, 19).

El Cacique de los Omaguas resulta ser un ejemplo de la noción de sujeto moderno presente en la literatura republicana: es la unión del indio noble, letrado, gran lector, partidario del sistema Lancaster, impregnado de orgullo americanista, producto de una formación en las ideas republicanas. Educado en Filadelfia es admirador de Estados Unidos y tiene por máximo valor la libertad, pero no la libertad individual o cualquier libertad, sino una de tipo republicana, una libertad situada en el marco de una nación cívicamente organizada, una nación de ciudadanos. Orientación que según el Cacique debía tomar "nuestra América" después del letargo de tres siglos de dominación española. Yari y el Cacique hablan con códigos que no son propios de ellos. La glorificación idealizada del mundo indígena es uno de los ideologemas básicos de la obra. La tesis del indio noble y del español bárbaro.

Debido a la necesidad de otorgarle tensión al drama y abrir la posibilidad de una anagnórisis, se produce en el Cacique un repentino y poco verosímil cambio de ánimo: a propósito de un manuscrito anuncia a la familia criolla que se ve forzado a entregarlos a los españoles. La posibilidad de salvación que les ofrece es que Camila contraiga vínculos de sangre y se case con un indígena para así naturalizarse en el país de los Omaguas, a lo que Camila por fidelidad a su marido se niega rotundamente. El Cacique le dice que le daría por esposo a Ministro: cuento corto, llaman al Ministro quien aparece en medio de los árboles, y se produce la anagnórisis, el Ministro es nada menos que el mismísimo don Diego, el marido desparecido de Camila al que daban por muerto. Artificial en este caso, la anagnórisis es un elemento propio del teatro clásico griego, como también lo son algunos elementos del vestuario que figuran en las indicaciones de la puesta en escena: las mujeres visten túnica larga de muselina blanca así como en los coros del teatro griego (con sombrero de rasgos nativos), y el Cacique con "camisa y calzón blanco, ancho y largo, a la asiática" (Henríquez, La Camila, 6).

Dardo Scavino identifica otro elemento vinculado al teatro griego: cuando el Jefe Omagua pone a prueba la fidelidad de Camila y ocultándole la presencia de don Diego le ofrece como esposo a su Ministro, luego que "Camila se niega" el Cacique le reprocha que los criollos siempre "prefieren a los españoles (enemigos de la patria)" y no a los nativos (Henríquez, La Camila, 22). Antes también les ha reprochado que los criollos nada hicieron cuando podrían haberle dado apoyo a Tupac Amaru "Visteis 
correr la sangre del alto príncipe y no derramasteis una lágrima" $(21)^{8}$. En este contexto, basándose en una referencia a una aria que canta don Diego, aria que es parte de una Ópera inspirada en una tragedia de Corneille (el más neoclásico de los dramaturgos modernos), Scavino plantea que el conflicto básico de la obra es el dilema al que se ve expuesta la protagonista, entre la fidelidad a la sangre (su marido y su familia) o a la alianza política (Omaguas y criollos americanos). Se trata, sin embargo, de un tema que se hace patente solo en la segunda mitad de la obra, un dilema que es más bien un artificio para darle tensión dramática al conflicto. Lo que sí es importante es la filiación que establece Scavino con el aria de Los Horacios y los Curiacios, ópera inspirada en una tragedia de Corneille, que añade un elemento neoclásico a la obra, tras ello reside el ideologema del humanismo universal.

Camila es patriota no de una nación determinada, sino de Sud América. Con frecuencia se hacen alusiones a la humanidad tanto por los criollos como por el Cacique y Yari. El lugar y la etnia elegidos para la acción no guardan ninguna relación con el sitio histórico del asunto. Cuando don José escucha que el Cacique piensa entregarlos a los españoles, le dice: “¿Y la compasión y la humanidad no hablan en vuestros corazón por nosotros?" (Henríquez, La Camila, 21). La causa por la que se lucha no es solo de un país, o de un continente, es una causa de la humanidad. La invocación a la humanidad y a la totalidad mundo aparece también en boca del Cacique. Después de su feliz reencuentro con don Diego, luego de que se conoce una propuesta emancipadora de Camila, el Cacique en un discurso con que finaliza la obra, la llama:

"¡Heroína del nuevo mundo! Imperturbable como las amazonas (cuyo suelo honráis con vuestras plantas), pero más culta que ellas y más sensible; yo he querido que vuestro digno esposo fuese testigo de vuestra fidelidad heroica y de vuestra singular ternura...Vuestras virtudes aparecerán algún día para la gloria de la Patria, admirables y excelsas, sobre los teatros del mundo" (38).

\section{GLORIFICACIÓN IDEALIZADA DEL MUNDO INDÍGENA}

La instalación en la obra de sujetos modernos (modelo asimilacionista que oculta la diferencia y la identidad de los pueblos originarios) es un elemento central en la pieza. $\mathrm{Y}$ es también un rasgo destacado del pensamiento republicano que se hace patente en periódicos, ensayos e incluso en el primer escudo nacional. Dentro de la matriz ilustrada, el republicanismo o humanismo cívico de Camilo Henríquez (también de Juan Egaña y Manuel de Salas) tiene diferencias con el liberalismo de la generación de 1842. Mientras que los primeros se ocupan de los derechos y de las libertades colectivas, los del 42 se centran más bien en los derechos y libertades individuales y en el binomio sarmientino de civilización y barbarie.

\footnotetext{
${ }^{8}$ De paso esa escena revela en el autor una coincidencia con la triple raigambre planteada por Simón Bolívar en la Carta de Jamaica (1815): por una parte los legítimos dueños del continente, por otra los criollos y por otra los invasores españoles, los del medio, en un dilema.
} 
Varios de los artículos de La Aurora tocan el tema araucano, el propio Camilo Henríquez escribió algunos usando un seudónimo mapuche: "Patricio Curiñacu". Reiteradamente idealiza a los araucanos:

\begin{abstract}
“Apenas habrá habido una nación más calumniada y oprimida, que la de nuestros compatriotas los indios. ¿Se creerá que hubo tiempo en que se dudó si eran racionales?... Sus bárbaros opresores los tuvieron por brutos porque pagaban a precio excesivo el cristal y otras especies... Más si el amor de la libertad, en sentir de Aristóteles, caracteriza a las almas fuertes, y generosas, y este amor es fecundo en sentimientos nobles y sublimes; jcuán grande aparece el carácter de nuestros hermanos los indios, que conservaron el amor de la libertad en medio del amor abatimiento, reducidos a la clase más abyecta de la sociedad, y a la haz del pueblo! Cuanto ardor, cuanto entusiasmo por la gran causa de la América han desplegado" (Henríquez, La Aurora 23, "El Editor” 96 Jueves 16 julio, 1812).
\end{abstract}

Sostuvo siempre y con optimismo la causa de la asimilación:

"los indios -escribió- están en estado de considerarse una nación nueva y por consiguiente fácil y dispuesta a ser ilustrada" (Henríquez, La Aurora 12, "Civilización de los indios" 51, jueves 30 abril,1812).

"Tal vez serán una de las glorias del Directorio los progresos literarios, que hagan en el Instituto (Nacional) los felices ingenios de estos nuestros compatriotas y hermanos, en quienes se conservan puros los rasgos de nuestro carácter nacional" (Henríquez, La Aurora "Prospecto"1, 2).

El pensamiento republicano en sintonía neoclásica percibía en el pasado indígena su propia época clásica, lo que inducía a un optimismo utópico en la perspectiva de la educación y la asimilación.

Varios historiadores han señalado el proceso de glorificación de La Araucanía que se dio en las primeras décadas del siglo XIX ${ }^{9}$. El adjetivo "araucano" llegó a ser -como señala Mario Góngora- un modo poético de decir "chileno". Los criollos independentistas se consideraban herederos legítimos de los araucanos, su coraje inspiró las primeras campañas contra el ejército realista. Simbolizaban el nuevo mito patrio. De allí que muchos de los títulos de diarios y organizaciones de ese período aludan a esta identificación. El periódico que en 1813 sucedió a la Aurora se tituló El Monitor Araucano, el primer diario oficial del Estado se llamó El Araucano; también hubo otros: El correo de Arauco, Década Araucana, Despertar Araucano, Ilustración Araucana e Insurgente Araucano. Una de las Logias Masónicas más importantes vinculadas a la Independencia fue la Logia Lautaro, también llamada Logia Lautarina. Además, como veremos luego, el Primer Escudo Chileno, de $1812^{10}$, mostraba una pareja de jóvenes indígenas al lado de una columna en cuya cúspide aparecía un globo, una lanza y una palma cruzada.

\footnotetext{
${ }^{9}$ Mario Góngora, Simón Collier, Holdenis Casanova y Viviana Gallardo, entre otros.

${ }^{10}$ Según todos los antecedentes con que se cuenta, ya que no existe un original.
} 
En 1813 la Junta que siguió al gobierno de Carrera promulgó un Reglamento a favor de los ciudadanos indios, declarando su propósito de hacer efectivas la fraternidad, igualdad y prosperidad de los indígenas, buscando superar la miseria, inercia e incivilidad en la que vivían abandonados. Juan Egaña, en 1819, publica sus Cartas Pehuenches, en que siguiendo el modelo de las Cartas Persas (1721) de Montesquieu, con espíritu crítico e ideario republicano dos Caciques dan cuenta de los vicios y virtudes en la postindependencia. No hay una sola línea en estas cartas en que pueda hablarse de una mirada o de un punto de vista propiamente indígena ${ }^{11}$.

Son posturas y discursos bien intencionados que ratifican el ideario republicano: alabanza y valoración simbólica del mundo indígena junto con el convencimiento de que deben abandonar su cultura para integrarse a una nación de ciudadanos, a una nación homogénea. Dentro de este panorama de glorificación idealizada del mundo indígena resulta explicable que Camilo Henríquez haya instalado un sujeto moderno en personajes indios al interior de La Camila, se trata de una invención que modifica el estado de cosas del mundo real, omitiendo las condiciones históricas de la existencia social de los pueblos originarios. Para el pensamiento republicano con influencia neoclásica en que se inscribe el ideario de Camilo Henríquez los mapuches simbolizaban el pasado clásico de Chile, los antecesores del momento de lucha que se estaba viviendo, en esta perspectiva su pensamiento se diferencia claramente de generaciones liberales posteriores que van a establecer -como ya señalamos- una dicotomía maniquiesta entre civilización y barbarie. Sin embargo, desde el punto de vista de la realidad social, la Independencia no implicó un cambio en las condiciones de vida de los pueblos originarios de América. Siguieron respecto de cada país en una marginalidad, aunque en Chile, en el caso de los Mapuche, no en el plano simbólico. Pero Henríquez, como queda claro en varios números de La Aurora (1812-1813), tenía un imaginario teleológico y utópico en que confiaba plenamente e incluso anticipaba que los indígenas se sumarían a las ideas y a la cultura republicana, en buenas cuentas serían asimilables a la modernidad. Utopía que está presente en la voluntad de composición de La Camila.

\footnotetext{
${ }^{11}$ Los saludos finales de cada una de las cartas en que se usan términos mapuches son meramente formales. Ver Bernardo Subercaseaux. "Prólogo y estudio preliminar", en Egaña, Juan. Cartas Pehuenches. Santiago: Colección Clásicos de la Literatura Chilena, 2002.
} 


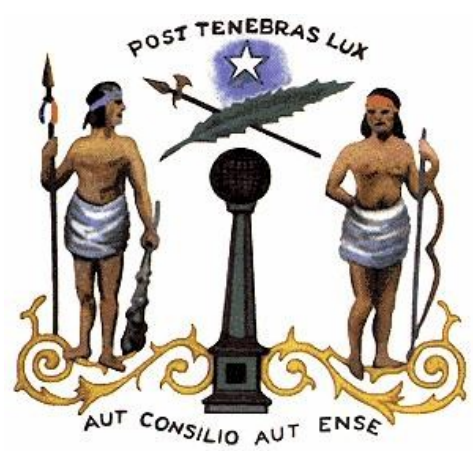

Primer Escudo Nacional (“Después de las tinieblas, la luz” y “O por consejo o por espada”)

\section{ESCUDO DE LA PATRIA VIEJA}

Vale la pena, a partir de lo señalado, examinar brevemente el Escudo de la Patria Vieja, en que de modo simbólico esta confluencia o mezcla del umbral previo y de las ideas modernas se hace graficamente patente, convergencia que opera también en la configuración de personajes, motivos y en la resolución de la obra de Henríquez. El primer escudo nacional habría sido ordenado por José Miguel Carrera en 1812, debido a que no se conserva el original la imagen ha sido compuesta a partir de descripciones de Manuel Talavera y fray Melchor Martínez, pero se puede considerar como verídica debido a que Talavera fue testigo presencial de la celebración en La Moneda del 30 de septiembre de 1812, en que se enarboló el Escudo de acuerdo con la imagen que antecede. También la crónica de Talavera da cuenta que de las 61 mujeres que asistieron al baile, dos de ellas, aunque eran criollas, estaban vestidas con traje de indias, para exaltar simbólicamente a su ancestro y patriotismo. En este primer escudo están presentes todas las matrices de sentido y los componentes culturales que hemos vislumbrado en la pieza teatral. La pareja de indígenas están idealizados en la medida que aparecen como tales en su vestimenta, pero inscritos en un marco de símbolos y lemas de la modernidad ilustrada. De partida los dictum en latín aunan el mundo clásico con las ideas de la ilustración, contraponiendo la oscuridad a la luz, lo premoderno, la superstición y la ignorancia al mundo moderno de la razón y la libertad. El ideario ilustrado dio lugar a un sistema metafórico lumínico en que enriquecen su sentido literal una larga serie de términos (rayo, relámpago, centella, chispa, apagar, encender, estrella, tinieblas, entre otros) que participan de este campo metafórico, campo que se percibe como universal. En este marco habría que leer también la aparición de Yari en la obra, el indio ilustre, que desciende del monte en medio de rayos y relámpagos.

La columna dórica y el globo que sustenta apuntan a dos matrices de sentido, por una parte al ideario republicano que alimentó la idea de comunidad a partir de la república griega, una república que no era solo una fórmula jurídica sino una mentalidad, una virtud, idea esta fundamental -como ha demostrado Mario Góngoraen el pensamiento de Juan Egaña. El republicanismo reconocía sus antecedentes en el 
mundo grecolatino. Por otra parte, el mundo sostenido por la columna dórica apunta a la universalidad de los emblemas contenidos en el escudo, a la idea de humanidad. Recordemos que uno de los artículos más relevantes redactados por Camilo Henríquez en La Aurora (7 de mayo de 1812) se titula "De la influencia de los escritos luminosos sobre la suerte de la humanidad". En la perspectiva de este pensamiento se es primero ser humano, parte de la humanidad y luego chileno, argentino, francés, araucano u otro. Planteamiento universalista y de modernidad-mundo presente en el imaginario visual que alimenta el escudo y también, como vimos, en los sujetos modernos de La Camila. El primer escudo tiene un aura pannacional en la medida que integra distintas tradiciones culturales en un cosmopolitismo republicano idealizado. Recordemos que la protagonista de la obra de Henríquez es proclamada por el Cacique a ser reconocida como "heroína" no de Chile o de Ecuador sino de los teatros del mundo. De ese mundo que en América por ser nuevo es apto como ningún otro -como lo dice el Caciquepara los logros de la razón y de la humanidad.

Sobre la base de unos sellos utilizados por el Estado en decretos y credenciales de 1814 y 1815, y también en una versión de Blanchard Chesi publicada en la Revista ZigZag de 1912, el estudioso Jose Miguel Barros señala la posibilidad de que las dos figuras del escudo no sean indígenas, sino dos personajes romanos. Esta sugerencia no invalida sino que confirma la idea republicana de un pasado aborigen pero que fue también clásico y de dignidad grecolatina. Nos parece, en todo caso, más plausible considerar como reales las imágenes reproducidas que se basan en los testimonios de Talavera y fray Melchor Martínez, pues las que muestra José Miguel Barros corresponden solo a sellos.

La naturaleza está presente en los laureles estilizados en que descansan los indígenas y también en la palma que se cruza con la alabarda. Una naturaleza que es sabia y bienhechora y que simboliza el progresismo en que se inscribe el carro de la historia: es la que sostiene el futuro. La estrella de 5 puntas que corona la imagen es un símbolo doble, por una parte es el pentaalpha de la masonería, emblema de la perfección y del supremo saber y por otra el weinalfe mapuche (nombre que asignaban al planeta Venus, imagen que Lautaro usó como pendón de guerra contra los españoles), emblema que está también en la estrella de 5 puntas de la primera bandera chilena. El mundo aborigen y el mundo criollo aparecen ensamblados. El conjunto de elementos que conforman el cuadro están, por tal razón, traspasados por un optimismo histórico, en que confluyen la naturaleza, las armas, la tradición grecolatina, y un mundo nuevo, apuntando a una modernidad híbrida hija de la europea, pero también con elementos aborígenes que la diferencian. Las lanzas nativas y la alabarda o espada occidentales están unidas y hermanadas, también las ideas. Lo que era heterogéneo y diverso está homogeneizado. Es lo mismo que ocurre en la pieza teatral de Camilo Henríquez. A pesar de la inspiración unionista del diseño (explicable dentro de una lucha supranacional contra la metrópoli) hay una apropiación, un afuera y un adentro conjugados, un emblema patrio en que se desvanece la diferencia, y se desconoce el desacomodo entre la utopía y el mundo real, 
entre lo europeo y lo nativo, entre la modernidad a la que se aspira y la sociabilidad colonial que subsiste.

\section{ASINCRONÍA E INORGANICIDAD}

Tanto el Primer Escudo como la obra de Camilo Henríquez articulan en el plano imaginario lo que no estaba articulado en la realidad. Un mundo indígena "civilizado" y desde una óptica ilustrada, pero que sin embargo carecía de sustento real en la época y hasta hoy. Estamos conscientes de que la imaginación utópica y la modificación del mundo real son instancias perfectamente legítimas tanto en la ficción como en los emblemas patrios. Pero también es legítimo leer y reflexionar a partir de ellos respecto de asincronías e inorganicidad histórica. Reflexionar acerca de las "repúblicas aéreas", de hechos de la época de la Independencia pero que de alguna manera han dejado una marca que se prolonga en todo el siglo XIX. No en balde José Martí en Nuestra América (1891) satirizó a esos letrados artificiales que sienten vergüenza del delantal de su madre india, y que en lugar de mirar la realidad de sus propios países viven pendientes de lo que ocurre en Europa, un Martí que señaló también que "nuestra Grecia es preferible a la Grecia que no es nuestra" (34).

Hay múltiples ejemplos de estas asincronías que revelan en cierta medida una simultaneidad entre la colonialidad y la modernidad, así como hemos planteado en otra oportunidad (Subercaseaux, Dónde estuvimos). El propio Camilo Henríquez vivió este desacomodo entre utopía republicana y realidad, a propósito de la cultura letrada. Cuando en 1811 llegó la primera imprenta a Chile Henríquez la bautizó como "la máquina de la felicidad".

"Está ya en nuestro poder -escribió- el precioso instrumento de la Ilustración Universal... Los sanos principios, el conocimiento de nuestros eternos derechos, las verdades sólidas y útiles va a difundirse entre todas las clases del Estado... la voz de la razón y de la verdad se oirán entre nosotros después del triste e insufrible silencio de tres siglos" (Henríquez, La Aurora, "Prospecto", 1).

Son frases hiperbólicas, sueños que portan una veneración por el libro y la cultura letrada, concibiéndolos como las herramientas fundamentales para la emancipación mental y la construcción de una nación acorde a las ideas de la modernidad. Frases que implican una política pública sobre la educación, el libro y la lectura. ¿Pero de qué libros se trataba? ¿Estaba pensando Camilo Henríquez en libros religiosos o de entretenimiento? La perspectiva religiosa y católica está casi ausente en sus escritos en La Aurora de Chile, como lo está también en La Camila. El fraile no estaba pensando, en consecuencia, ni en vidas de santos, ni en devocionarios, ni en almanaques u otros géneros livianos procedentes de España. Pensaba, como señala en varios de sus escritos, en "libros útiles y morales" (así se decía en la época): libros proveedores de conocimiento, que contribuyeran al ejercicio de la razón, al pensamiento 
autónomo y crítico, a la formación de una sensibilidad estética y al desarrollo de una virtud republicana en la perspectiva de los ideales ilustrados.

En el mundo real, sin embargo, lo que ocurría distaba mucho de las posibilidades para implementar esa utopía. La aletargada sociabilidad colonial seguía operando. Un sector de los patricios criollos tenían intereses económicos para los cuales los lemas de igualdad, fraternidad y libertad resultaban algo amenazantes. Apenas el 10\% de la población del país sabía leer. John Miers, ingeniero inglés que estuvo en Chile varios años a partir de 1818, refiriéndose a la educación y la lectura escribió lo siguiente:

"los chilenos son ignorantes, y proclaman con cierto orgullo que no requieren del conocimientro de los libros. Tienen además muy pocos y los pocos que tienen no los leen" (56).

Miers se refería a la élite y a algunos patriarcas de la oligarquía local:

"Recuerdo - señala- que el Presidente del Senado, un hombre respetado por sus compatriotas... una voz respetada y escuchada... alardeaba de no haber examinado un libro durante 30 años, y otro funcionario principal del Gobierno, quien se jacta de ser un hombre 'culto y erudito' insinúa que 'para él el conocimiento extraído de los libros resulta innecesario"' (Miers, 68).

Hay otros testimonios de extranjeros que corroboran lo señalado por Miers, entre ellos de los viajeros ingleses Alexander Caldcleugh y María Graham (Subercaseaux, Literatura y prensa). El propio Camilo Henríquez se refirió más tarde a la escasez de lectores, otro tanto hizo Andrés Bello en 1829, recién llegado al país. En un texto de 1814 titulado significativamente Ensayo acerca de los sucesos desastrosos de Chile, Henríquez reconociendo la parcialidad republicana de su punto de vista en escritos anteriores, y velando por observaciones imparciales, señaló lo siguiente:

"Si se hubiese pedido entonces a algún observador imparcial y reflexivo que señalase el camino que debía seguirse para evitar los futuros males, él debía haber dicho a los chilenos: las formas republicanas están en contradicción con vuestra educación, religión, costumbres y hábitos de cada una de las clases" (Amunátegui, Las primeras representaciones teatrales, 186).

En definitiva, reconocía que la modernidad propiciada por sus escritos estaba temporalmente fuera de lugar, esto en un texto de 1814. En la obra teatral de 1817 lo que hace es adecuarla, zurcir las asincronías y darle consistencia ficticia a esa utopía en una obra que por su misma carencia de una verdad de fondo resulta por momentos demasiado conceptual y en términos teatrales no plenamente lograda.

Ahora bien, si pensamos, el siglo XIX resulta evidente -y ya Bolívar así lo plantea en la Carta de Jamaica (1815)- que las utopías de la élite ilustrada republicana postindependencia eran en algunos aspectos impracticables, ya que carecían de un suelo histórico apropiado. Sin embargo, paradojalmente, eran también indispensables. Formuladas en el aire y sin piso, pero con fe ideológica, esos planteamientos van a dar 
pie a una verdadera "posta" de ideales que van a quedar en el imaginario y que de algún modo incidirían en cambios futuros de la sociedad chilena y americana. Son planes a largo plazo en una nación que está en sus albores.

\section{UN PUNTO DE VISTA ACTUAL}

Hasta el momento hemos mirado la obra de Henríquez y el contexto de ideas en que esta se escribió situándonos en el punto de vista decimonónico, en una línea que va desde Camilo Henriquez hasta José Martí. Si nos salimos de esa burbuja y adoptamos una mirada crítica a la situación actual de los pueblos originarios pensando desde una óptica de emancipación y diversidad cultural, tenemos que hacer otras observaciones. La aspiración de incorporar al indígena en igualdad de condiciones con los criollos ilustrados, así como ocurre en La Camila y en el primer escudo nacional, significaba, en los hechos, que se negaba lo indio como cultura y como espacio de diferencia. Y es que para pertenecer a la nación los aborígenes debían necesariamente despojarse de los que los hacía diferentes, es decir, de su identidad, solo desde ahí podían acceder a la ciudadanía, al proyecto de una sociedad moderna. Perspectiva asimilacionista que al operar solo simbólicamente resultó a la postre excluyente y que históricamente pavimentó el camino para la "pacificación" en la segunda mitad del siglo XIX.

La supuesta universalidad ilustrada (presente en la obra de Henríquez) que jurídicamente se suponía operante, disfrazaba una realidad de inequidades y una marcada exclusión y discriminación social. La conciencia crítica de este disfraz ha tenido su fruto en países latinoamericanos en que hay alta población aborigen. En historiadores, cientistas sociales y escritores, como José Carlos Mariátegui y José María Arguedas en Perú, Augusto Roa Bastos en Paraguay, Miguel Ángel Asturias en Guatemala, Gonzalo Bofill y Juan Rulfo en México, Ernesto Cardenal en Nicaragua, José Bengoa y Elicura Chihuailaf en Chile, autores que tematizando sus circunstancias locales se hicieron cargo del patrimonio conflictivo de América Latina, de una realidad que por un lado fue obra modernizadora de espíritu renacentista, ilustrado y republicano, y por otra apocalipsis e invisibilidad de las culturas autóctonas.

Desde esta perspectiva es posible también pensar la virtualidad ingenuamente colonizadora de la operación realizada por Camilo Henríquez, instalando un modelo de sujeto exógeno y europeo en personajes indios, en una obra que probablemente fue leída en un contexto literario estrecho y excluyente, en que el mercado cultural era marcadamente elitista, por no decir oligárquico. Basta leer los principales diarios y revistas del siglo XIX para percatarse que el estilo de vida afrancesado y ostentoso de lo europeo impregnaba la estructura y la fisonomía de la sociedad en distintas dimensiones. Un testimonio de un viajero inglés en 1887, acerca de nuestro país, señalaba lo siguiente: "Los chilenos llaman a su metrópoli el París americano. En realidad Santiago no es sino un trozo de París, injertado en una aldea de indios" (Catalán, 82). 
Esta opinión, marcadamente eurocéntrica, da lugar a preguntarse si es que la perspectiva asimilacionista de Camilo Henríquez, bien intencionada pero que en los hechos resultó excluyente, ¿no guarda acaso una relación con la opinión antes citada?

Si regresamos, empero, a 1817, al modelo de sociedad postulado en la obra, un modelo de convivencia entre criollos e indígenas en que los mitos de la superioridad e inferioridad se diluyen, nos daremos cuenta que se trata de una convivencia en la modernidad en que tampoco los criollos salen indemnes, y en que queda en evidencia quiénes son los legítimos dueños del continente, quiénes tienen ciertos derechos por nacimiento y quiénes son los invasores.

En conclusión, se puede señalar que La Camila o la patriota de Sud América, aun cuando es una obra de teatro menor, tiene importancia como documento y fuente histórica para conocer el pensamiento republicano y sus principales ideologemas (naturaleza como paradigma de la historia, filiación neoclásica, humanismo universal, glorificación idealizada del mundo indígena, asimilacionismo en la perspectiva de la modernidad), ideologemas que están también presentes en el primer escudo nacional, y que contemplados desde hoy -en que se respeta y valora la diversidad cultural- permite mirar críticamente algunos de esos bien intencionados y patrióticos planteamientos, realizados en años en que todavía no se decidía la emancipación definitiva de las colonias.

\author{
Universidad de Chile* \\ Facultad de Filosofia y Humanidades \\ Ignacio Carrera Pinto 1025 Nuñoa (Chile) \\ besuberc@uchile.cl \\ Universidad de Chile** \\ Licenciatura en Letras Hispánicas \\ Ignacio Carrera Pinto 1025 Nuñoa (Chile) \\ paula.cuadraaros@gmail.com
}

\title{
OBRAS CITADAS
}

Amunátegui, Luis Miguel. Camilo Henríquez. Tomo I. Santiago: Imprenta Nacional, 1889.

— Las primeras representaciones teatrales en Chile. Santiago: Imprenta Nacional, 1888.

Barros Franco, José Miguel. "Acerca del primer escudo de Chile". Boletín de la Academia de la Historia. 1996: 17-30.

Catalán, Gonzalo. "Antecedentes de la transformación del campo literario en Chile entre 1880 y 1920". Cinco estudios sobre la cultura y la sociedad. Santiago: Flacso, 1985: 71-175.

Egaña, Juan. Cartas Pehuenches. Santiago: Colección Clásicos de la Literatura Chilena, 2002. Faúndez, Tania. "La guerra en la dramaturgia chilena". Tesis Doctoral, Universidad Autónoma de Barcelona, Barcelona, 2014. 
Gallardo, Viviana. "Héroes indómitos, bárbaros y ciudadanos chilenos: el discurso sobre el Indio en la construcción de la identidad nacional". Revista de Historia Indígena. 2001: $\mathrm{N}^{\circ} 5$.

Góngora, Mario. Estudios de historia de las ideas y de la historia social. Valparaíso: Universitarias de Valparaíso, 1980.

Henríquez, Camilo. La Camila o la Patriota de Sud América. Buenos Aires: Imprenta Benavente y Ca., 1817. Memoria Chilena. Rescatado el 10 de agosto de 2014. Disponible en: http://www.memoriachilena.cl/602/w3-article-8309.

__ "Prospecto". La Aurora de Chile. 13 de Febrero 1812: 1-3.

"Moción de Agustín Argüelles para abolir la esclavitud". La Aurora de Chile. 30 de Abril 1812: 52-53.

"De la influencia de los escritos luminosos sobre la suerte de la humanidad". $\mathrm{La}$ Aurora de Chile. 7 de Mayo 1812.

"Editor". La Aurora de Chile. 16 de Julio 1812: 96.

"Del entusiasmo revolucionario". La Aurora de Chile. 10 Sept. 1812: 130-132.

Martí, José. Nuestra América. Caracas: Biblioteca Ayacucho, 2005.

Miers, John. "Travels in Chile and La Plata, Baldwin". Trad. Gonzalo Piwonka. Cuadernos de Historia. Mar. 2009: 149 - 191.

Pereira Salas, Eugenio. Historia del teatro en Chile. Desde sus origenes hasta la muerte de Juan Casacuberta. Santiago: Universidad de Chile, 1974.

Pradenas, Luis. Teatro en Chile. Huellas y trayectorias. Santiago: LOM, 2006.

Scavino, Dardo. "La Camila de Camilo Henríquez o el dilema corneliano de la minoría criolla”. Cuadernos Lírico. Puesto en línea el 1 septiembre 2013. Rescatado el 29 enero 2015. Disponible en: http://lirico.revues.org/1171

Subercaseaux, Bernardo. “¿Dónde estuvimos, dónde estamos y hacia dónde vamos con el libro y la lectura?". Ojo con las lecturas. Anales de la Universidad de Chile, $\mathrm{N}^{\mathrm{o}}$ 6, Santiago, 2014, 39-56.

"Literatura y prensa de la Independencia., independencia de la literatura". Katia Carrillo y Monika Weltcheim (editoras). Literatura de la Independencia. Frankfurt: Biblioteca Iberoamericana, 2012, 19-43.

Talavera, Manuel. "Descripción del baile en la Casa de Moneda en septiembre de 1812". Crónicas de la Patria Vieja Chilena. Rescatado el 17 nov. 2014. Disponible en: https://patriavieja.wordpress.com/category/septiembre-de-1812/

Urbina, Leandro. El sueño ilustrado. Santiago: USACH, 2011.

—_ "La Camila o la patriota de Sud América", texto inédito preparado para Historia crítica de la literatura chilena, obra en desarrollo. 